\title{
Factors that influence blood loss and need for transfusion following total knee arthroplasty
}

\author{
Achilleas Boutsiadis ${ }^{1}$, Ryan Jacob Reynolds ${ }^{2}$, Mo Saffarini ${ }^{2}$, Jean-Claude Panisset ${ }^{1}$ \\ ${ }^{1}$ Department of Orthopaedic Surgery, Centre Osteoarticulaire des Cèdres, Grenoble, France; ${ }^{2}$ Medical Technology, ReSurg SA, Nyon, Switzerland \\ Contributions: (I) Conception and design: A Boutsiadis, M Saffarini, JC Panisset; (II) Administrative support: A Boutsiadis, M Saffarini, JC Panisset; (III) \\ Provision of study materials or patients: A Boutsiadis, JC Panisset; (IV) Collection and assembly of data: A Boutsiadis, JC Panisset; (V) Data analysis \\ and interpretation: RJ Reynolds, M Saffarini; (VI) Manuscript writing: All authors; (VII) Final approval of manuscript: All authors. \\ Correspondence to: Mo Saffarini, MEng. Medical Technology, ReSurg S.A., Chemin de la Vuarpillière 35, 1260 Nyon, Switzerland. \\ Email: journals@resurg.eu.
}

Background: Blood loss during total knee arthroplasty (TKA) remains a concern, as many patients require blood transfusions, which increase risks of allergic reactions, disease transmission, and thromboembolisms. The purpose was to determine factors associated with blood loss and need for transfusion in patients receiving routine TKA.

Methods: The authors prospectively analyzed 150 consecutive uncemented TKAs for age, gender, body mass index (BMI), anticoagulant medication, type of anesthesia, tranexamic acid (TXA) administration, tourniquet inflation, drain placement, pre- and post-operative Haemoglobin $(\mathrm{Hb})$ level $(\mathrm{g} / \mathrm{dL})$, and whether transfusion was necessary. Univariable and multivariable regression analyses were performed to identify factors associated with $\mathrm{Hb}$ loss and need for transfusion with significance level set at $\mathrm{P}$ value $<0.05$.

Results: The cohort comprised 92 women and 58 men, aged $69.5 \pm 8.9$ years. The mean Hb loss was $3.7 \pm 1.3 \mathrm{~g} / \mathrm{dL}$. The 20 patients $(13 \%)$ who had transfusions also had lower preoperative $\mathrm{Hb}(12.6 \pm 1.2 \mathrm{~g} / \mathrm{dL})$ compared to the remaining patients $(14.3 \pm 1.2 \mathrm{~g} / \mathrm{dL})$. Hb loss was significantly associated with preoperative $\mathrm{Hb}$, TXA, and gender, but multivariable regression identified gender as a confounder and indicated that TXA reduced $\mathrm{Hb}$ loss by $0.92 \mathrm{~g} / \mathrm{dL}$. Multivariable regression revealed the need for transfusion was only significantly associated with preoperative $\mathrm{Hb}$ and indicated that a decrease of preoperative $\mathrm{Hb}$ by $1 \mathrm{~g} / \mathrm{dL}$ nearly quadrupled the chances of needing transfusion.

Conclusions: $\mathrm{Hb}$ loss was significantly associated with preoperative Hb levels and use of TXA, while the need for transfusion was only associated with preoperative Hb levels. These findings could help identify patients at risk for blood transfusions. Level of evidence: level III, prospective case series.

Keywords: Total knee arthroplasty (TKA); blood loss; transfusion; tranexamic acid (TXA); anticoagulants; Hb level

Submitted Jul 25, 2017. Accepted for publication Jul 31, 2017.

doi: 10.21037/atm.2017.08.11

View this article at: http://dx.doi.org/10.21037/atm.2017.08.11

\section{Introduction}

Blood loss during total knee arthroplasty (TKA) remains a concern, as $18 \%$ to $67 \%$ of patients require blood transfusion following their operation (1-3). Allogenic transfusions increase risks of allergic reactions, hemolytic reaction, 30-day mortality, disease transmission, surgical- site infection, periprosthetic infections, and venous thromboembolisms (4-8). For these reasons, several measures have been introduced and evaluated to limit blood loss during and following TKA, including the use of tourniquets, autologous blood transfusion, drain clamping or retransfusion drains, computer assisted surgery, hypotensive anesthesia, and patient-specific instruments, as 
well as various pharmaceuticals (2,9-12).

The efficacy and drawbacks of these blood management strategies are frequently debated. While erythropoietin $(11,13)$ and antifibrinolytic drugs such as tranexamic acid (TXA) (14-20) are known to be effective with limited side effects, fibrinogen and fibrin sealants were recently found ineffective $(21,22)$, despite disagreement with earlier studies (23). Likewise, the use of tourniquets reduced blood loss intraoperatively, but not postoperatively, hence a diminished net effect, as well as risks of bruising, neurovascular injury, and metabolic disturbance $(24,25)$. Most other solutions such as drain clamping, computer assisted surgery, and patient-specific instruments demonstrated little or no benefit $(2,9,12)$.

Due to the continued high transfusion rates and the compounding effect of risk factors, Noticewala et al. (26) examined 31 factors to determine variables associated with blood loss and need for transfusion. Their multivariable analysis concluded that age, preoperative haemoglobin $(\mathrm{Hb})$, and surgical time were significant factors in predicting the need for transfusion, though they did not consider the use of TXA (26).

The purpose of this study was, therefore, to determine patient factors (age, gender, BMI, anticoagulant use, preoperative $\mathrm{Hb}$ ) and surgical factors (tourniquet, TXA, drain, and type of anesthesia) associated with blood loss and need for transfusion in a consecutive series of TKA performed by a single surgeon. The clinical relevance of this study is the findings could help identify patients at increased risk of blood loss and need for transfusion.

\section{Methods}

The authors prospectively enrolled 151 consecutive patients that underwent TKA for tibiofemoral osteoarthritis (OA) between April 2015 and January 2016. All patients were operated through a standard medial parapatellar approach by an experienced surgeon using uncemented tibial and femoral components as well as a cemented patellar button (T-KAPS, X.NOV, Hericourt, France). One patient was excluded due to a hematological disorder (myeloma).

For the remaining 150 patients, the following information was documented: age, gender, body mass index (BMI), and detailed medical history. In addition, the following perioperative parameters were recorded:

(I) Anticoagulant drugs (yes/no), such as Clopidogrel, Aspirin and non-steroidal anti-inflammatory drugs (NSAIDs), which were stopped 1 week prior to surgery $(\mathrm{n}=39)$;

(II) Type of anesthesia (regional/general);

(III) TXA administration (yes/no), followed a standard protocol of a bolus dose of $15 \mathrm{mg} / \mathrm{kg}$ three minutes after starting anesthesia, and a continuous perfusion of $1 \mathrm{mg} / \mathrm{kg} / \mathrm{h}$ during the operation. Patients were contraindicated by prothrombotic conditions or previous thromboembolic events including deep vein thrombosis (DVT) $(\mathrm{n}=17)$, pulmonary embolism $(\mathrm{n}=2)$, myocardial infarction $(n=5)$, stroke $(n=7)$, coronary artery stent $(n=14)$, or bypass graft $(n=4)$;

(IV) Tourniquet inflation (yes/no), depended on the patient arterial pressure, use of anticoagulants, and whether TXA was administered;

(V) Drain placement (yes/no), used to prevent swelling in patients with excessive intra-operative bleeding. The drain had negative suction for one hour and was removed after 24 hours;

(VI) Preoperative $\mathrm{Hb}(\mathrm{g} / \mathrm{dL})$ level, collected two or three days before the operation, during preoperative assessment;

(VII) Postoperative $\mathrm{Hb}(\mathrm{g} / \mathrm{dL})$ level, collected during routine postoperative assessments;

(VIII) $\mathrm{Hb}$ loss $(\mathrm{g} / \mathrm{dL})$, calculated as the difference between preoperative $\mathrm{Hb}$ level and the lowest recorded postoperative $\mathrm{Hb}$ level;

(IX) Blood transfusion (yes/no), administrated in accordance with established ASA guidelines $(\mathrm{n}=20)(27)$.

Postoperatively, all patients received low molecular weight heparin $(\mathrm{LMWH})$ as a thrombosis prophylaxis and NSAIDs were avoided. The presence of DVT was evaluated for all patients through routine ultrasonography (Triplex) of both lower limbs at 48 hours and 5 days. The ethical review board of our hospital approved this study (IRB\# 2015-01).

\section{Statistical analysis}

Statistical analyses were performed using $\mathrm{R}$ version 3.3.3 (R Foundation for Statistical Computing, Vienna, Austria). Descriptive statistics were used to summarize the data. For non-Gaussian quantitative data, between group differences were evaluated using Wilcoxon rank sum tests (Mann Whitney $U$ test). Categorical data were analyzed using Pearson chi-square tests or Fisher's exact tests. Univariable and multivariable linear ( $\mathrm{Hb}$ loss) and ordinal (transfusions) regression analyses were performed to identify factors 
Table 1 Patient demographics

\begin{tabular}{ll}
\hline Patient specifics & Cohort $(\mathrm{n}=150)$ \\
\hline Age & $69.5 \pm 8.9(50.0-91.0)$ \\
$\mathrm{BMI}\left(\mathrm{kg} / \mathrm{m}^{2}\right)$ & $28.5 \pm 5.1(17.9-45.4)$ \\
Preoperative $\mathrm{Hb}(\mathrm{g} / \mathrm{dL})$ & $14.0 \pm 1.3(10.2-17.8)$ \\
Male gender & $58(38.7 \%)$ \\
Preoperative anticoagulants & $39(26.0 \%)$ \\
\hline
\end{tabular}

Table 2 Descriptive surgical results

\begin{tabular}{lc}
\hline Intraoperative observations & Cohort $(\mathrm{n}=150)$ \\
\hline Surgery & $45(30 \%)$ \\
Tourniquet & \\
Type of anesthesia & $100(67 \%)$ \\
Regional & $50(33 \%)$ \\
General & $44(29 \%)$ \\
Surgical drain & $101(67 \%)$ \\
TXA & $20(13 \%)$ \\
Transfusion & \\
Complications & $3.7 \pm 1.3(0.9-7.7)$ \\
Hb loss (g/dL) & $15(10 \%)$ \\
DVT & $1(0.7 \%)$ \\
Infection & \\
\hline
\end{tabular}

TXA, tranexamic acid; Hb, hemoglobin; DVT, deep vein thrombosis.

associated with outcomes. The factors considered were patient age, BMI, preoperative $\mathrm{Hb}$, gender, anticoagulant use, tourniquet use, type of anesthesia, drain use, and TXA administration.

\section{Results}

The cohort comprised 92 women and 58 men, aged $69.5 \pm 8.9$ years (Table 1 ). Regional anesthesia was administered in 100 patients $(67 \%)$, the tourniquet was inflated in $45(30 \%)$, TXA was administered in 101 patients (67\%), the drain was used in $44(29 \%)$, and a transfusion was necessary in 20 (13\%) (Table 2). DVT developed in 7 of the 101 patients $(7 \%)$ who received TXA compared to 8 of the 49 patients $(16 \%)$ who did not receive TXA $(\mathrm{P}=0.116)$. The mean Hb loss was $3.7 \pm 1.3 \mathrm{~g} / \mathrm{dL}$.
Univariable regression revealed that $\mathrm{Hb}$ loss was significantly associated with: preoperative $\mathrm{Hb}(\mathrm{P}<0.001)$, TXA $(\mathrm{P}=0.029)$, and gender $(\mathrm{P}<0.001)$ (Table 3$)$. Multivariable regression clarified that $\mathrm{Hb}$ loss was directly associated with preoperative $\mathrm{Hb}(\mathrm{P}<0.001)$, TXA $(\mathrm{P}<0.001)$, and drain placement $(\mathrm{P}=0.044)$, but not with gender (n.s.). Adjusting for confounding variables, an increase of preoperative $\mathrm{Hb}$ by $1 \mathrm{~g} / \mathrm{dL}$ was found to increase $\mathrm{Hb}$ loss by $0.37 \mathrm{~g} / \mathrm{dL}$, while use of TXA was found to reduce $\mathrm{Hb}$ loss by $0.92 \mathrm{~g} / \mathrm{dL}$ (Figure 1).

Univariable regression revealed that the need for transfusion was significantly associated with: age $(\mathrm{P}=0.041)$, anticoagulants $(\mathrm{P}<0.001)$, preoperative $\mathrm{Hb}(\mathrm{P}<0.001)$, and TXA $(\mathrm{P}<0.001)$ (Table 4). Multivariable regression clarified that the need for transfusion was only directly associated with preoperative $\mathrm{Hb}(\mathrm{P}<0.001)$. Adjusting for confounding variables, a decrease of preoperative $\mathrm{Hb}$ by $1 \mathrm{~g} / \mathrm{dL}$ nearly quadrupled the chances of needing transfusion. In fact, patients that needed transfusions had preoperative $\mathrm{Hb}$ of $12.6 \pm 1.2$ (median 12.7; range, 10.2-14.6) compared to $14.3 \pm 1.2$ (median 14.2; range, 11.4-17.8) for patients that did not need transfusions (Figure 2).

\section{Discussion}

The most important finding from this consecutive series of TKA was that, accounting for confounding variables, the need for blood transfusion was only associated with patient preoperative $\mathrm{Hb}$ levels. Furthermore, the total $\mathrm{Hb}$ loss was significantly associated with preoperative $\mathrm{Hb}$ levels (direct relationship) as well as TXA administration (inverse relationship).

The purpose of this study was to determine patient and surgical factors associated with blood loss and need for transfusion in a consecutive series of TKA performed by a single surgeon. Our findings are in agreement with several studies that reported how preoperative $\mathrm{Hb}$ is significantly associated with blood loss and the need for transfusion (26,28-32). In particular, Noticewala et al. (26) evaluated the association of 31 factors with blood loss and need for transfusion during TKA. After adjusting for confounding variables, they found age, preoperative $\mathrm{Hb}$, and surgical time to have significant effect, though they did not consider the use of TXA (26). Also, routine arthroplasty has a reported $\mathrm{Hb}$ loss of $3.8 \mathrm{~g} / \mathrm{dL}$, which is comparable to the $3.7 \mathrm{~g} / \mathrm{dL}$ observed in the present study (33).

Both Hatzidakis et al. (31) and later Guerin et al. (30) reported that patients undergoing lower extremity total 
Table 3 Regression analysis of $\mathrm{Hb}$ loss $(\mathrm{g} / \mathrm{dL})$

\begin{tabular}{|c|c|c|c|c|c|c|}
\hline \multirow[b]{2}{*}{ Variable } & \multicolumn{3}{|c|}{ Univariable } & \multicolumn{3}{|c|}{ Multivariable } \\
\hline & $\begin{array}{l}\text { Regression } \\
\text { coefficient }\end{array}$ & $95 \% \mathrm{Cl}$ & $P$ value & $\begin{array}{c}\text { Regression } \\
\text { coefficient }\end{array}$ & $95 \% \mathrm{Cl}$ & $P$ value \\
\hline \multicolumn{7}{|l|}{ Continuous $^{1}$} \\
\hline Age (years) & 0.0 & $(0.0$ to 0.0$)$ & 0.145 & 0.0 & (0.0 to 0.0$)$ & 0.177 \\
\hline Preoperative Hb (g/dL) & 0.4 & (0.2 to 0.5$)$ & $<0.001$ & 0.4 & $(0.2$ to 0.6$)$ & $<0.001$ \\
\hline \multicolumn{7}{|l|}{ Catagorical $^{2}$} \\
\hline Gender (male vs. female) & 0.7 & (0.3 to 1.1$)$ & $<0.001$ & 0.2 & $(-0.3$ to 0.7$)$ & 0.398 \\
\hline Anticoagulant (yes vs. no) & 0.1 & $(-0.4$ to 0.6$)$ & 0.693 & 0.0 & $(-0.5$ to 0.5$)$ & 0.907 \\
\hline Drain placement (yes vs. no) & 0.3 & $(-0.2$ to 0.7$)$ & 0.246 & 0.4 & (0.0 to 0.8$)$ & 0.044 \\
\hline TXA (yes vs. no) & -0.5 & $(-0.9$ to 0.1$)$ & 0.029 & -0.9 & $(-1.4$ to 0.4$)$ & $<0.001$ \\
\hline
\end{tabular}

${ }^{1}$, Regression coefficient represents the expected difference in $\mathrm{Hb}$ loss for an increase of the independent variable by one unit; ${ }^{2}$, Regression coefficient represents the expected difference in $\mathrm{Hb}$ loss for the specified binary category. BMI, body mass index; Hb, hemoglobin; TXA, tranexamic acid.

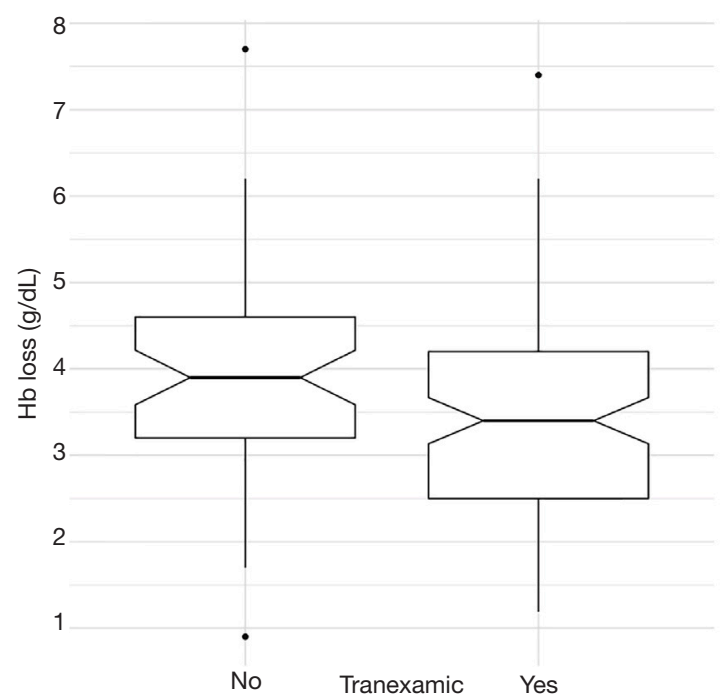

Figure 1 Haemoglobin $(\mathrm{Hb})$ loss in patients that did or did not receive tranexamic acid (TXA).

joint arthroplasty with preoperative $\mathrm{Hb}$ levels $<13 \mathrm{~g} / \mathrm{dL}$ were 4 (31) to 5.6 (30) times more likely to need transfusion relative to those with $\mathrm{Hb}$ levels $>15 \mathrm{~g} / \mathrm{dL}$. Furthermore, Salido et al. (34) advocated that patients with preoperative $\mathrm{Hb}>15 \mathrm{~g} / \mathrm{dL}$ rarely need blood transfusion. Similarly, our data revealed that patients who needed transfusions had preoperative $\mathrm{Hb}$ of $12.6 \pm 1.2$ compared to $14.3 \pm 1.2$ for patients that did not need transfusions, and multivariable regression indicated that a decrease of preoperative $\mathrm{Hb}$ by $1 \mathrm{~g} / \mathrm{dL}$ nearly quadrupled the chances of needing transfusion. Several blood management algorithms use preoperative $\mathrm{Hb}$ levels to predict the need for transfusion, and were found effective in limiting transfusion $(11,26,35)$. However, Kapadia et al. (36) conclude that these algorithms need to be evaluated further by prospective randomized studies.

Our findings also confirmed that TXA significantly reduced blood loss without increasing the incidence of thromboembolism $(17,37)$. Review articles focusing on the prediction of blood transfusion after joint arthroplasty concluded that drugs intended to reduce blood loss, such as TXA, have significantly lowered the need for transfusion $(15,16,32,38-40)$. However, these drugs are simply one part of the solution required to limit bleeding and transfusion rates $(32,40)$. For instance, we have evidence that the surgical drain increased blood loss. Therefore, when a drain is placed, retransfusion drains $(41,42)$ or drain clamping techniques (2) should be considered in order to reduce blood loss. 
Table 4 Regression analysis of need for transfusion

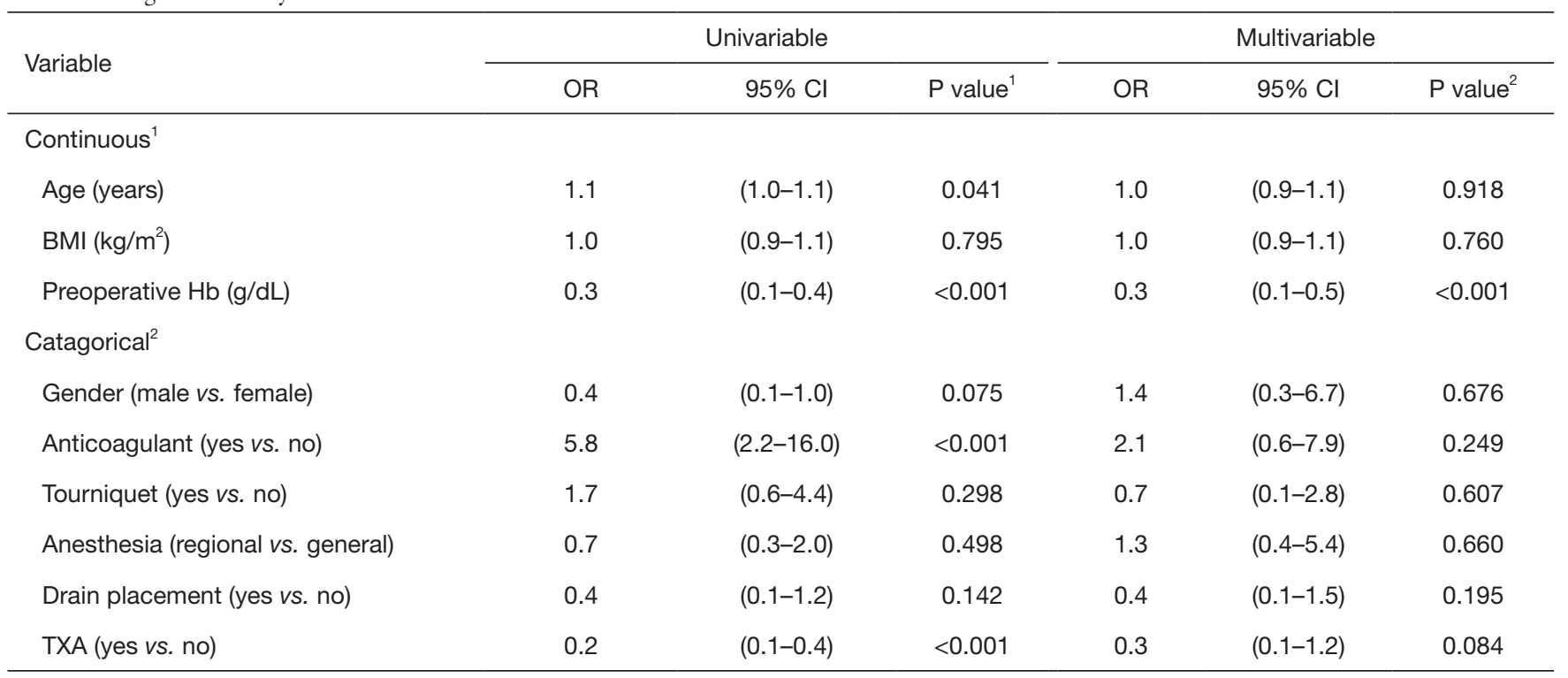

${ }^{1}$, odds ratio of needing transfusion for an increase of the independent variable by one unit; ${ }^{2}$, odds ratio of needing transfusion for the specified binary category. OR, odds ratio; BMI, body mass index; Hb, hemoglobin; TXA, tranexamic acid.

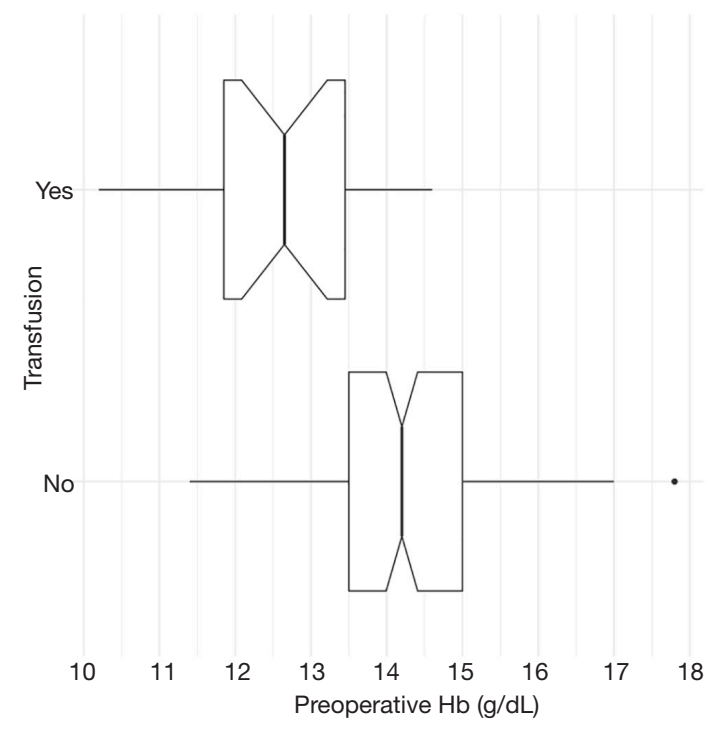

Figure 2 Pre-operative haemoglobin $(\mathrm{Hb})$ levels in patients that did or did not require blood transfusions.

Blood management strategies are often debated. While TXA is known to be effective, patients with thromboembolic events and conditions often contraindicate its administration $(35,40)$. Topical application of TXA is perhaps as effective as intravenous administration, and is not contraindicated $(35,43-45)$. Erythropoietin is an effective means of increasing preoperative $\mathrm{Hb}$, but may not be cost effective (13). Autologous blood transfusion may also not be cost effective, but it has been recommended for anemic patients as long as sufficient time is permitted to replenish red blood cells (46-49). A common reason for anemia is iron deficiency, which can be corrected by intravenous or oral iron supplement $(35,36)$. Intravenous infusion is expected to improve Hb by $1 \mathrm{~g} / \mathrm{dL}$ over 10 days (35). However the effectiveness of iron supplementation in reducing the need for transfusion is controversial (36). Previous studies showed that the use of tourniquets does not significantly reduced blood loss due to the slight increase in blood loss postoperatively $(9,24,25)$. Use of tourniquet also has risks of bruising, neurovascular injury, and metabolic disturbance $(9,25)$. Also, computer assisted surgery and patient-specific instruments aid in surgery, though they have limited effect on reducing blood loss (9). Further research should be done on pharmaceuticals, devices, and other measures to determine the best solutions to managing blood loss and the need for transfusion.

The present study has a number of limitations typical of non-comparative observational studies. Firstly, TXA was administered in all patients unless contraindicated by prothrombotic conditions or previous thromboembolic events. While TXA was found to significantly reduce blood loss, it is not certain whether this observation is directly 
related to the use of TXA or to the contra-indications for its use. Secondly, type of anesthesia, tourniquet inflation and drain placement depended upon several subjective factors, which could induce bias. Thirdly, the relatively small number of transfusions $(n=20)$ may not have enabled detection of all associated factors. The main strength of the study is that it analyzed multiple factors that could influence blood loss and the need for transfusion in the routine practice of a single surgeon using the same implant and surgical technique.

\section{Conclusions}

The findings of this study confirm that, accounting for confounding variables, the need for blood transfusions during our routine TKA procedures depends primarily on patients' preoperative Hb levels. TXA significantly reduces blood loss but did not directly influence the need for transfusion. These findings could help identify patients at risks of excessive blood loss and need for transfusions, to ensure the necessary measures are taken to limit blood loss.

\section{Acknowledgements}

The authors are grateful to Mr. Luca Nover for his assistance with manuscript and tables preparation.

\section{Footnote}

Conflicts of Interest: The authors have no conflicts of interest to declare.

Ethical Statement: The ethical review board of our hospital approved this study (IRB\# 2015-01).

\section{References}

1. Bierbaum BE, Callaghan JJ, Galante JO, et al. An analysis of blood management in patients having a total hip or knee arthroplasty. J Bone Joint Surg Am 1999;81:2-10.

2. Chareancholvanich $K$, Siriwattanasakul P, Narkbunnam $\mathrm{R}$, et al. Temporary clamping of drain combined with tranexamic acid reduce blood loss after total knee arthroplasty: a prospective randomized controlled trial. BMC Musculoskelet Disord 2012;13:124.

3. Hart A, Khalil JA, Carli A, et al. Blood transfusion in primary total hip and knee arthroplasty. Incidence, risk factors, and thirty-day complication rates. J Bone Joint
Surg Am 2014;96:1945-51.

4. Bernard AC, Davenport DL, Chang PK, et al. Intraoperative transfusion of $1 \mathrm{U}$ to $2 \mathrm{U}$ packed red blood cells is associated with increased 30-day mortality, surgical-site infection, pneumonia, and sepsis in general surgery patients. J Am Coll Surg 2009;208:931-7, 937.e12; discussion 938-9.

5. Browne JA, Adib F, Brown TE, et al. Transfusion rates are increasing following total hip arthroplasty: risk factors and outcomes. J Arthroplasty 2013;28:34-7.

6. Dwyre DM, Fernando LP, Holland PV. Hepatitis B, hepatitis $\mathrm{C}$ and HIV transfusion-transmitted infections in the 21st century. Vox Sang 2011;100:92-8.

7. Fernandez MC, Gottlieb M, Menitove JE. Blood transfusion and postoperative infection in orthopedic patients. Transfusion 1992;32:318-22.

8. Kato H, Nakayama T, Uruma $M$, et al. A retrospective observational study to assess adverse transfusion reactions of patients with and without prior transfusion history. Vox Sang 2015;108:243-50.

9. Banerjee S, Issa K, Kapadia BH, et al. Intraoperative nonpharmacotherapeutic blood management strategies in total knee arthroplasty. J Knee Surg 2013;26:387-93.

10. Jung WH, Chun CW, Lee JH, et al. No difference in total blood loss, haemoglobin and haematocrit between continues and intermittent wound drainage after total knee arthroplasty. Knee Surg Sports Traumatol Arthrosc 2013;21:2831-6.

11. Su EP, Su S. Strategies for reducing peri-operative blood loss in total knee arthroplasty. Bone Joint J 2016;98-B:98-100.

12. Thienpont E, Grosu I, Paternostre F, et al. The use of patient-specific instruments does not reduce blood loss during minimally invasive total knee arthroplasty? Knee Surg Sports Traumatol Arthrosc 2015;23:2055-60.

13. Bedair H, Yang J, Dwyer MK, et al. Preoperative erythropoietin alpha reduces postoperative transfusions in THA and TKA but may not be cost-effective. Clin Orthop Relat Res 2015;473:590-6.

14. Aguilera X, Martinez-Zapata MJ, Hinarejos P, et al. Topical and intravenous tranexamic acid reduce blood loss compared to routine hemostasis in total knee arthroplasty: a multicenter, randomized, controlled trial. Arch Orthop Trauma Surg 2015;135:1017-25.

15. Alshryda S, Sukeik M, Sarda P, et al. A systematic review and meta-analysis of the topical administration of tranexamic acid in total hip and knee replacement. Bone Joint J 2014;96-B:1005-15. 
16. Kim TK, Chang CB, Koh IJ. Practical issues for the use of tranexamic acid in total knee arthroplasty: a systematic review. Knee Surg Sports Traumatol Arthrosc 2014;22:1849-58.

17. Panteli M, Papakostidis C, Dahabreh Z, et al. Topical tranexamic acid in total knee replacement: a systematic review and meta-analysis. Knee 2013;20:300-9.

18. Seo JG, Moon YW, Park SH, et al. The comparative efficacies of intra-articular and IV tranexamic acid for reducing blood loss during total knee arthroplasty. Knee Surg Sports Traumatol Arthrosc 2013;21:1869-74.

19. Zhang H, Chen J, Chen F, et al. The effect of tranexamic acid on blood loss and use of blood products in total knee arthroplasty: a meta-analysis. Knee Surg Sports Traumatol Arthrosc 2012;20:1742-52.

20. Zhao-Yu C, Yan G, Wei C, et al. Reduced blood loss after intra-articular tranexamic acid injection during total knee arthroplasty: a meta-analysis of the literature. Knee Surg Sports Traumatol Arthrosc 2014;22:3181-90.

21. Bernasek TL, Burris RB, Fujii H, et al. Effect on blood loss and cost-effectiveness of pain cocktails, platelet-rich plasma, or fibrin sealant after total knee arthroplasty. J Arthroplasty 2012;27:1448-51.

22. Randelli F, D'Anchise R, Ragone V, et al. Is the newest fibrin sealant an effective strategy to reduce blood loss after total knee arthroplasty? A randomized controlled study. J Arthroplasty 2014;29:1516-20.

23. Li ZJ, Fu X, Tian P, et al. Fibrin sealant before wound closure in total knee arthroplasty reduced blood loss: a meta-analysis. Knee Surg Sports Traumatol Arthrosc 2015;23:2019-25.

24. Jiang FZ, Zhong HM, Hong YC, et al. Use of a tourniquet in total knee arthroplasty: a systematic review and metaanalysis of randomized controlled trials. J Orthop Sci 2015;20:110-23.

25. Parvizi J, Diaz-Ledezma C. Total knee replacement with the use of a tourniquet: more pros than cons. Bone Joint J 2013;95-B:133-4.

26. Noticewala MS, Nyce JD, Wang W, et al. Predicting need for allogeneic transfusion after total knee arthroplasty. J Arthroplasty 2012;27:961-7.

27. Apfelbaum JL, Nuttal GA, Connis RT, et al. Practice guidelines for perioperative blood management: an updated report by the American Society of Anesthesiologists Task Force on Perioperative Blood Management. Anesthesiology 2015;122:241-75.

28. Carling MS, Jeppsson A, Eriksson BI, et al. Transfusions and blood loss in total hip and knee arthroplasty: a prospective observational study. J Orthop Surg Res 2015;10:48.

29. Frisch NB, Wessell NM, Charters MA, et al. Predictors and complications of blood transfusion in total hip and knee arthroplasty. J Arthroplasty 2014;29:189-92.

30. Guerin S, Collins C, Kapoor H, et al. Blood transfusion requirement prediction in patients undergoing primary total hip and knee arthroplasty. Transfus Med 2007;17:37-43.

31. Hatzidakis AM, Mendlick RM, McKillip T, et al. Preoperative autologous donation for total joint arthroplasty. An analysis of risk factors for allogenic transfusion. J Bone Joint Surg Am 2000;82:89-100.

32. Sizer SC, Cherian JJ, Elmallah RD, et al. Predicting Blood Loss in Total Knee and Hip Arthroplasty. Orthop Clin North Am 2015;46:445-59.

33. Pierson JL, Hannon TJ, Earles DR. A bloodconservation algorithm to reduce blood transfusions after total hip and knee arthroplasty. J Bone Joint Surg Am 2004;86-A:1512-8.

34. Salido JA, Marin LA, Gomez LA, et al. Preoperative hemoglobin levels and the need for transfusion after prosthetic hip and knee surgery: analysis of predictive factors. J Bone Joint Surg Am 2002;84-A:216-20.

35. Liu D, Dan M, Martinez Martos S, et al. Blood Management Strategies in Total Knee Arthroplasty. Knee Surg Relat Res 2016;28:179-87.

36. Kapadia BH, Banerjee S, Issa K, et al. Preoperative blood management strategies for total knee arthroplasty. J Knee Surg 2013;26:373-7.

37. Gillette BP, DeSimone LJ, Trousdale RT, et al. Low risk of thromboembolic complications with tranexamic acid after primary total hip and knee arthroplasty. Clin Orthop Relat Res 2013;471:150-4.

38. Shemshaki H, Nourian SM, Nourian N, et al. One step closer to sparing total blood loss and transfusion rate in total knee arthroplasty: a meta-analysis of different methods of tranexamic acid administration. Arch Orthop Trauma Surg 2015;135:573-88.

39. Banerjee S, Issa K, Pivec R, et al. Intraoperative pharmacotherapeutic blood management strategies in total knee arthroplasty. J Knee Surg 2013;26:379-85.

40. Melvin JS, Stryker LS, Sierra RJ. Tranexamic Acid in Hip and Knee Arthroplasty. J Am Acad Orthop Surg 2015;23:732-40.

41. Dutton T, De-Souza R, Parsons N, et al. The timing of tourniquet release and 'retransfusion' drains in total knee arthroplasty: A stratified randomised pilot investigation. Knee 2012;19:190-2. 
42. Oremus K, Sostaric S, Trkulja V, et al. Influence of tranexamic acid on postoperative autologous blood retransfusion in primary total hip and knee arthroplasty: a randomized controlled trial. Transfusion 2014;54:31-41.

43. Chen JY, Chin PL, Moo IH, et al. Intravenous versus intra-articular tranexamic acid in total knee arthroplasty: A double-blinded randomised controlled noninferiority trial. Knee 2016;23:152-6.

44. Wang H, Shen B, Zeng Y. Blood Loss and Transfusion After Topical Tranexamic Acid Administration in Primary Total Knee Arthroplasty. Orthopedics 2015;38:e1007-16.

45. Meena S, Benazzo F, Dwivedi S, et al. Topical versus intravenous tranexamic acid in total knee arthroplasty. J Orthop Surg (Hong Kong) 2017;25:2309499016684300.

Cite this article as: Boutsiadis A, Reynolds RJ, Saffarini M, Panisset JC. Factors that influence blood loss and need for transfusion following total knee arthroplasty. Ann Transl Med 2017;5(21):418. doi: 10.21037/atm.2017.08.11
46. Spahn DR. Anemia and patient blood management in hip and knee surgery: a systematic review of the literature. Anesthesiology 2010;113:482-95.

47. Cip J, Widemschek M, Benesch T, et al. Does single use of an autologous transfusion system in TKA reduce the need for allogenic blood?: a prospective randomized trial. Clin Orthop Relat Res 2013;471:1319-25.

48. Park JH, Rasouli MR, Mortazavi SM, et al. Predictors of perioperative blood loss in total joint arthroplasty. J Bone Joint Surg Am 2013;95:1777-83.

49. Sabatini L, Atzori F, Revello S, et al. Intravenous use of tranexamic acid reduces postoperative blood loss in total knee arthroplasty. Arch Orthop Trauma Surg 2014;134:1609-14. 